\title{
LUGAR DE MULHER: UMA ABORDAGEM HISTÓRICA SOBRE A PARTICIPAÇÃO FEMININA NAS MANIFESTAÇÕES DE ATIVISMO JUVENIL NO BRASIL
}

\author{
Beatriz Beraldo \\ biaberaldob@gmail.com \\ Pontifícia Universidade Católica do Rio de Janeiro - Brasil
}

Recibido: 12-02-2016

Aceptado: 13-05-2016

\section{Resumo}

Este artigo realiza um breve histórico da participação das jovens brasileiras nos principais movimentos sociais que ocorreram no Brasil nos últimos 50 anos, dando especial destaque à chegada da Segunda Onda Feminista ao país e às novas formas de ativismo juvenil no ambiente virtual do século XXI. Para tanto, valemo-nos de uma extensa revisão bibliográfica com o intuito de dar conta do nosso pré-concebido recorte de gênero.

Palavras-Chave: Juventude, mulher; ativismo juvenil, feminismo.

\begin{abstract}
This article carries out a brief history of the participation of young Brazilian women in major social movements that took place in Brazil in the last 50 years, with special emphasis on the arrival of the Second Feminist Wave in this country and the new forms of youth activism in the virtual environment of the 21 st century. To this end, we make use of an extensive literature review aiming to account our preconceived gender clipping.
\end{abstract}

Keywords: Youth, woman, youth activism, feminism. 


\section{Introdução}

É fácil perceber que o debate em torno do ativismo juvenil ganhou bastante destaque na pauta midiática e no campo acadêmico nos últimos anos, especialmente devido às grandes manifestações que ocorreram ao redor do mundo, a exemplo da Primavera Árabe, do $15 \mathrm{M}$ Espanhol, do Occupy Wall Street. Tais manifestações estão ligadas a protestos que podem ser de viés político ${ }^{1}$ e/ou ideológico, abrangendo discussões sobre aprovações de leis, mudanças de comportamento, dentre outros tantos temas. No Brasil, diante das grandes manifestações de junho de 2013, a atenção ao ativismo juvenil foi então redobrada. Pensando nessa questão, este artigo busca, a partir de um recorte de gênero, abordar a participação feminina nos movimentos sociais de ativismo juvenil no Brasil desde a emblemática década de 1960 até encontrar as novas versões de ativismo que ganharam força no início do século XXI, contando com a indispensável ajuda do novo aliado de inúmeros jovens, a rede social digital Facebook.

Como afirma Cláudia Pereira (2010), "há muito mais do que rebeldia, música e moda na juventude e este parece ser o motivo de grandes investimentos em pesquisas." (Pereira, 2010: 39). Desse modo, buscamos aqui demonstrar alguns dos principais momentos da história do Brasil contemporâneo que contaram com a participação das jovens ativistas em sua conformação. Em seguida, daremos destaque às ações de juventude que se relacionam com as questões de gênero, levando em conta as novas modalidades de ativismos dentro das redes sociais digitais.

\section{Movimentos Sociais e Juventude}

Nos movimentos sociais, os setores juvenis ganham destaque, pois estão atrelados às características comumente associadas às imagens estereotipadas de "rebeldia", "selvageria" e "transgressão", na perspectiva abordada por João Freire Filho (2007), nomeada como sendo a caracterização do "jovem desviante".

A juventude é cobrada por determinados setores adultos a ser engajada, participativa e ativa politicamente, pois se acredita que "todo partido revolucionário encontra primeiramente um apoio na nova geração da classe ascendente" (Trotsky, 1968: 31). Para a pesquisadora Ana Enne (2010), a juventude pode ser compreendida como "certo espírito do tempo, relacionado às rupturas, ao novo, ao que não se conforma, à busca por experiências e mudanças" (Enne, 2010: 19). Similarmente, João Freire Filho ressalta que os jovens são "normalmente vistos como sismógrafos, barômetros ou catalisadores de mudanças na produção e no consumo cultural, nos

\footnotetext{
${ }^{1}$ Concebendo a ideia de política não necessariamente ligada a um plano institucional e/ ou partidário.
} 
comportamentos e nas relações sociais" (Freire Filho, 2007: 22). Concordando com os autores, ressaltamos a importância de se estudar a juventude nos contextos de mudanças sociais.

A noção de juventude que conhecemos hoje é fruto do pós-guerra, momento em que se passa a falar de uma "cultura jovem". No entanto, a liderança juvenil em movimentos sociais, em uma perspectiva mundial, somente ganha visibilidade e reconhecimento a partir dos anos 1960, momento em que os (e as) jovens, com as "chaves de casa" nas mãos, ganharam as ruas, no Brasil e no mundo. As jovens mulheres, por sua vez, começam timidamente, também por volta dos anos 1960, a tomar a pílula anticoncepcional. Portanto entende-se que esse momento marca o surgimento de uma juventude "mais crítica e politizada [que] negou a cultura vigente, até então sustentada e manipulada em sua maior parte pela indústria cultural" (Brandão e Duarte, 2004: 16). Essa participação jovem específica junto aos movimentos sociais e culturais ficou conhecida como contracultura, onde também se inserem as mais significativas manifestações feministas do século XX. Foi assim, em meio a essa grande e complexa rede de eventos, rupturas e marcos históricos dos anos 1960, que começou

“[...] a se engendrar a efetiva apropriação pelos jovens de discursos, produtos e espaços midiáticos, algo claramente associado à consolidação de uma sociedade de consumo já totalmente sensível ao processo que autores como Edgar Morin (1984) - na linha de frente

- definem como uma ‘juvenilização’ da cultura” (Borelli; Rocha; Oliveira, 2009: 13).

No Brasil, é também a partir da década de 1960 que a juventude passa a protagonizar os movimentos sociais em contextos estudantis e culturais, a partir de agrupamentos como a UNE (União Nacional dos Estudantes), que "discutia as questões nacionais e as perspectivas de transformação que mobilizavam o país" (Brandão e Duarte, 2004: 73). Para a pesquisadora Rose de Melo Rocha, esse cenário só se torna possível diante da, até então inédita, circulação dos jovens nos espaços públicos:

“Aos jovens de 60 e 70, apresenta-se uma ruptura importante, materializada pelo que seria um verdadeiro 'abandono do lar'. Não mais restritos aos espaços fechados, da casa aos bailes, os jovens passam a ocupar os espaços públicos, as ruas, as praias, locais que, cada vez mais, lhes servirão de palco. Uma renovação ímpar das fronteiras estabelecidas entre o público e o privado estava sendo anunciada" (Rocha, 2012b: 246).

\section{Participação da juventude feminina em movimentos sociais}

Os movimentos sociais podem ser definidos como "ações coletivas realizadas em vista de um objetivo, cujo resultado, em caso de sucesso como em caso de fracasso, transforma os 
valores e as instituições da sociedade" (Castells, 1999: 538). O movimento feminista é também considerado um movimento social em razão de alguns fatores:

"O que permite principalmente caracterizar o movimento feminista como movimento social é a sua duração. Quaisquer que sejam as intermitências da mobilização, as mulheres não cessaram de lutar coletivamente desde a Revolução Francesa. Ademais, esse movimento se enraíza nas contradições fundamentais da sociedade, nascidas tanto do desenvolvimento do capitalismo como da persistência até hoje da dominação masculina, que se exprime na divisão social e sexual do trabalho" (Trat, 2009: 151-152).

Os anos 1960 marcam o início da "Segunda Onda do Feminismo". Diferente da "Primeira Onda", que esteve principalmente centrada na reivindicação de direitos políticos, a "segunda onda" deu prioridade às lutas contra o patriarcado ${ }^{2}$ e pelo direito à autonomia do corpo e ao prazer com o slogan mundialmente conhecido: "o privado é político".

Não é despropositadamente que a década de 1960 é conhecida como a década "que mudou o mundo" (Rocha, 2012b: 247). Há também, nas abordagens juvenis características dessa década, o destaque para as questões da mulher e o fortalecimento do movimento feminista, especialmente no Brasil. Sobre esse momento histórico, Gilles Lipovetsky (2000) ressalta:

“Ao longo dos anos 60, instala-se uma nova problemática que já não pensa a sexualidade como o lugar fechado de um domínio privado, mas como uma relação de poder entre os gêneros, um dispositivo de essência política”.

No entanto, o surgimento da "Segunda Onda Feminista" teria começado com o atraso de uma década - nos anos 1970 - no Brasil, conforme observa Pedro (2006):

"Uma das narrativas fundadoras do feminismo da Segunda Onda no Brasil informa que, graças à definição, pela ONU — Organização das Nações Unidas, de 1975 como o Ano Internacional da Mulher, e como ano de início da Década da Mulher, aconteceu no Brasil o ressurgimento do movimento feminista 'organizado'. Este teria sido inaugurado com uma reunião, ocorrida em julho de 1975, na ABI - Associação Brasileira de Imprensa, no Rio de Janeiro, e com a constituição do Centro da Mulher Brasileira, também naquela cidade. A partir de então, teria ocorrido o aparecimento de outros espaços de união e movimento feminista em outros lugares do Brasil” (Pedro, 2006: 250).

\footnotetext{
2 "O patriarcado designa uma formação social em que os homens detêm o poder, ou ainda, mais simplesmente, o poder é dos homens. Ele é, assim, quase sinônimo de 'dominação masculina' ou de opressão das mulheres" (Delphy, 2009: 173).
} 
Outros movimentos sociais e culturais, que contam com a participação das jovens mulheres brasileiras, e que têm o seu início nessa época são: a Bossa Nova e o Cinema Novo. A participação dos e das jovens nesse momento histórico vivido pela sociedade brasileira foi, sem dúvida, fundamental para definir os rumos que tomaria o país. O contexto da ditadura militar, que teve início em 1964, é também marcado pela consolidação das discussões críticas sobre políticas de identidades, dentre elas as questões da mulher, em claro enfrentamento à lógica repressiva capitaneada pelos militares de então. A recusa radical da juventude aos valores do golpe entrava em cena por meio de "cabelos longos, roupas coloridas, misticismo oriental, muita música e drogas" (Carmo, 2000: 51). As articulações brasileiras saem de dentro dos campi universitários, a exemplo do grande evento de Maio de 68, na França ${ }^{3}$.

Em 1968, ano emblemático para os movimentos sociais com participação estudantil, o Brasil "tinha um pouco mais de 270 mil universitários, correspondente a apenas $0,3 \%$ da população" (Carmo, 2000: 84). No entanto, essa pequena parcela da população exerceu papel muito significativo: "tornaram-se porta-vozes do descontentamento contra a ditadura militar e, mais tarde, serviram de quadros para a esquerda clandestina" (idem).

Em 28 de março daquele ano, a morte do estudante Edson Luís durante uma manifestação no Rio de Janeiro, foi o estopim para uma grande mobilização juvenil. O pesquisador Paulo Sérgio do Carmo (2000) relembra que, logo depois, em $1^{\circ}$ de abril, os estudantes saem às ruas:

“Agora como quem vai para guerra. Portando paus e pedras, paralisam o centro do Rio. Depredam agências bancárias e lojas, reviram carros oficiais, queimam um automóvel e danificam outros veículos. Apanhar ou correr da polícia já estava se tornando rotina [...] O auge das manifestações se dá com a histórica Passeata dos Cem Mil, no Rio de Janeiro, reunindo estudantes, intelectuais, artistas, padres e mães. Para aquela época, 100 mil manifestantes era um número assustador. Mesmo que a quantidade real de manifestantes na passeata fosse menor, o fato é que dessa vez, o regime de 1964 estava tão acuado e exposto que a Passeata dos Cem Mil chegou a assustar os militares" (Carmo, 2000: 85-86).

Nesse período de fortes contestações culturais, a jovem Leila Diniz, atriz e estrela do cinema e da televisão brasileira, destacou-se como símbolo da libertação feminina em consequência dos seus "inúmeros namoros, sexo livre e linguajar pouco convencional para a maioria das mocinhas da sua época" (Carmo, 2000: 119). Além disso, um episódio marca a vida de Leila e a história das jovens mulheres daquela época: a atriz vai à praia e se deixa fotografar grávida, usando apenas o seu biquíni. A sua atitude recebeu críticas dos conservadores (incluindo mulheres) que escreveram para jornais demonstrando repudiar o ocorrido. Sem citar

\footnotetext{
${ }^{3}$ O movimento social de maio de 1968 aconteceu em Paris e teve o seu início com a força da juventude que promoveu greves estudantis. Para Olgária Matos "[e]ssa não foi uma luta pelo poder ou contra ele; afirmaram-se, ao contrário, os direitos da subjetividade e da espontaneidade consciente. Com a crítica ao mundo burocratizado e desencantado, colocou como lema a verdade triunfante do desejo" (Matos, 1998: 13).
} 
o nome do Jornal, Carmo (2000: 119) afirma que um deles endossou o protesto e se posicionou dizendo que era contrário "à exibição vulgar de um estado de graça que é a maternidade". Leila, morta aos 27 anos em um trágico acidente, foi a primeira figura pública brasileira a enfrentar com naturalidade o machismo naquele regime militar.

O aparecimento das lutas feministas no cenário político brasileiro não foi bem recebido por toda a população. Muitos cidadãos e cidadãs entendiam o feminismo equivocadamente como um "machismo ao contrário" e, diante disso, opunham-se a ele. Algumas jovens mulheres, inclusive, entendiam o movimento como um agrupamento de mulheres "mal-amadas", histéricas, feias e/ou homossexuais, características às quais elas não queriam ser associadas (Zanetti, 2008). Por esse motivo, destacamos a importância de Leila Diniz como força de visibilidade para as questões da mulher naquele momento, pois:

"[e]stas representações [equivocadas] sobre o feminismo e suas militantes, compartilhadas não só pelas jovens, mas também por boa parte da população, foram construídas ao longo da história, com participação de vários setores da sociedade, inclusive de alguns considerados progressistas. Um exemplo disto é O Pasquim, jornal alternativo publicado a partir de 1969, que teve seu auge na metade dos anos 1970. Segundo Soihet (2005), apesar de inspirado na contracultura norte-americana, voltado para o combate ao autoritarismo nacional, inúmeras vezes este impresso assumiu postura misógina, ridicularizando feministas e desqualificando suas reivindicações (Zanetti, 2008: 04-05)”.

No Brasil e no mundo, o movimento feminista sempre contou com a participação da juventude, embora esta não seja muito destacada nos estudos específicos sobre o tema. Para a pesquisadora Julia Paiva Zanetti (2010), esses poucos registros são fruto de uma relação com a juventude que seria permeada por desconfianças sobre a inexperiência, pois "as jovens militantes não possuem uma longa vivência ou um profundo conhecimento do movimento, nem representam instituições ou têm títulos que as legitimem" (Zanetti, 2010: 02). Neste sentido, ainda na perspectiva de Zanetti (2010), a juventude seria enxergada como "herdeira" do movimento feminista, vista "como uma possibilidade de continuidade do legado do movimento" (idem). A pesquisadora destaca ter observado, na fala de jovens feministas de São Paulo, queixas sobre a dificuldade de se fazerem ouvir ao ingressarem em movimentos feministas já consolidados.

Por outro lado, faz-se necessário lembrar que a maioria dos estudos sobre a juventude, por sua vez, também não assume como ênfase a distinção de gênero, conforme esclarece Rossana Reguillo (2012):

"Muitas vezes, e num tom muito próximo ao "politicamente correto", observou-se a ausência de reflexão e estudo sobre as mulheres jovens, e se nota em diversas investigações realizadas até agora, pelo menos na América Latina, que elas tampouco têm 
lidado com homens jovens. Isto é, a literatura disponível tende a ser uma generalização onde a diferença entre os sexos é invisível. Com poucas exceções, não tem sido suficientemente problematizado o fato de que os grupos e coletivos de jovens sejam formados em sua maioria por homens. Esta omissão ignora a presença das mulheres, subsumidas - quando aparecem - a uma abordagem que não contempla as diferenças de participação, representação e expressão entre elas e eles" (Reguillo, 2012: 71) ${ }^{4}$.

Esse fator torna mais difícil a nossa abordagem, que busca verificar a participação feminina dentro dos movimentos sociais e a participação da juventude nos movimentos feministas.

Zanetti (2008), mais uma vez, traz à tona a perspectiva de que a juventude brasileira só veio aparecer oficialmente como participante ativa da sociedade há poucas décadas, quando foram desenvolvidas as primeiras políticas públicas que beneficiaram especificamente essa categoria. Além disso, o movimento feminista, desde a sua segunda onda, pautou-se no que Bondi (2000) trata como "colocar hífens":

"As mulheres começaram a se identificar como feminista-negra, feminista-proletária, feminista-lésbica, feminista-judia e assim sucessivamente. Igual que com as primeiras iniciativas de conscientização feminista, os grupos que foram formados ao redor dessas etiquetas procuraram, ao compartilhar experiências, compreender a natureza de sua opressão de uma forma que conduzia à resistência” (Bondi, 2000: 258).

Todavia observaram-se resistências dentro do próprio movimento feminista, o que fez com que as jovens não se formatassem em uma nova etiqueta, como "feministas-jovens", por exemplo. Ao contrário, segundo Zanetti (2008), as jovens feministas procuraram se inserir nesses outros agrupamentos identitários, já formatados e considerados mais sólidos.

As jovens mulheres, segundo Zanetti (2008), ainda que não ganhassem o merecido destaque, só estiveram realmente afastadas das manifestações feministas durante o período da década de 90. Anteriormente, estiveram sempre presentes, embora seja pouco provável encontrar estudos que abordem essa participação:

"Nos anos de 1990, o feminismo sofreu certo retraimento, que teve como uma de suas características a falta de renovação do movimento, marcada pelo raro ingresso de jovens

\footnotetext{
${ }^{4}$ Tradução nossa. Trecho original: Con frecuencia, y en un tono bastante cercano a 'lo políticamente correcto', se señala la ausencia de reflexión y estudio sobre las mujeres jóvenes, y se ignora que una gran cantidad de las investigaciones realizadas hasta ahora, por lo menos en América Latina, tampoco se ha ocupado de los hombres jóvenes. Es decir, en la literatura disponible se tiende a una generalización que invisibiliza la diferencia de género. Salvo honrosas excepciones, no se ha problematizado suficientemente el hecho de que los grupos y colectivos juveniles estén formados en su mayoría por varones. Esta omisión deja de lado la presencia femenina, subsumida - si aparece - por un enfoque que no atiende a las diferencias de participación, representación y expresión entre ellas y ellos. (Reguillo, 2012: 71).
} 
militantes. Aparentemente não houve interesse das jovens em se aproximar do movimento, tão pouco parece ter havido uma preocupação das feministas, pelo menos que se revertesse em algum tipo de ação, de conquistar as novas gerações” (Zanetti, 2008: 03).

As jovens brasileiras, entretanto, não abandonam os movimentos sociais e as práticas políticas. Na década de 90 , embora não se tenham dados da sua participação em movimentos feministas, é possível localizá-las nas ruas, encampando o movimento denominado caras pintadas, que pressionou o Congresso Nacional a abrir o processo de impeachment (impedimento do exercício oficial pelo ocupante de um cargo público) contra o presidente Fernando Collor de Mello, que renunciou momentos antes de ser declarado impedido (Brandão e Duarte, 2004).

O final dos anos 90, no Brasil, foi marcado pela estabilização da economia com o Plano Real, criado pelo Presidente Fernando Henrique Cardoso, que permaneceu no cargo por dois mandatos (1995-2002). Mais uma vez, encontramos uma lacuna sobre a participação da juventude feminina nesse período no Brasil. No final da década de 90 e início dos anos 2000, todavia, a juventude ganha força e destaque inauditos na história do movimento feminista. Essa reaproximação da juventude ao movimento feminista é provavelmente justificada por alguns dos fatores a seguir:

"Por exemplo, a observação sobre os dados quantitativos e qualitativos sobre saúde reprodutiva (gravidez, aborto, uso de métodos contraceptivos etc.), ou violência de gênero junto às jovens permite verificar [que] as relações desiguais de gênero ainda coloca [as jovens mulheres] em lugar de submissão aos interesses e desejos dos homens, ou seja, as conquistas históricas do feminismo em relação ao próprio corpo e aos direitos sexuais e reprodutivos não estão sendo plenamente incorporadas e usufruídas pelas novas gerações, o que indica também uma ausência de ações do movimento voltadas para este público" (Zanetti, 2008: 05) ${ }^{5}$.

É nos anos 2000 também que o processo de institucionalização das demandas feministas no Brasil alcança uma grande vitória com o advento da Lei 11.340, de 7 de agosto de 2006, a chamada Lei Maria da Penha ${ }^{6}$, "que de forma inédita cria mecanismos para coibir a violência doméstica e familiar contra a mulher, estabelecendo medidas para a prevenção, assistência e proteção às mulheres em situação de violência” (Piovesan, 2011: 62). A juventude feminista,

\footnotetext{
${ }^{5}$ Grifo nosso.

${ }^{6}$ A lei 11.340, de 7 de agosto de 2006, ficou conhecida por este nome em homenagem a Maria da Penha, mulher que sofreu, em 1983, duas tentativas de assassinato por seu marido que a deixaram paraplégica. Mesmo condenado por tribunais locais, o réu valeu-se de recursos processuais e não foi preso. Maria da Penha recorreu à Comissão Interamericana de Direitos Humanos. Em 2001 o Brasil foi responsabilizado por omissão e negligência.
} 
desse modo, segundo Piovesan, vê-se contribuindo ativamente para a melhoria da qualidade de vida da mulher no país.

Um dos mais destacados sintomas desse retorno da juventude às manifestações, em especial das jovens brasileiras, seria o surgimento das denominadas "marchas juvenis" com temática especificamente feminista, a exemplo da Marcha Mundial das Mulheres, Marcha das Margaridas e Marcha das Vadias que trazem novamente, para o espaço público, questões da vida doméstica, abordando temas como a submissão e violência de gênero.

\section{Ativismo Digital}

Para compreender melhor o contexto em que surgem as marchas juvenis que abordam a temática feminista, faz-se necessário compreender como se dá a sua organização na esfera virtual, que invariavelmente antecede e acompanha a ocupação das ruas. A internet tem revelado ser o lugar de articulação das marchas juvenis não só no Brasil, como em todo mundo. Mais precisamente, as ferramentas escolhidas pelos jovens para esse tipo de organização e agrupamento são as redes sociais digitais, sendo a mais destacada delas o Facebook. Esse recurso virtual tem sido o grande aliado dos jovens ativistas nas mais diversas manifestações que ocorreram neste início de século. Como nos relembram Figueiredo e Prazeres:

"Pode-se dizer que o Facebook tornou-se uma ferramenta de grande importância para a eclosão de manifestações como a Primavera Árabe ao proporcionar um espaço democrático e transformador. A exemplo das recentes manifestações, podemos observar que a rede social permitiu que através de recursos como o compartilhamento de vídeos e imagens, bem como a criação de eventos, a população árabe se mobilizasse e modifícasse as tradicionais maneiras de articulação, tornando cidadãos em jornalistas e fonte de informação para o mundo" (Figueiredo e Prazeres, 2013: 58).

Esse agenciamento das militâncias políticas através da internet foi denominado pelos próprios usuários e, posteriormente, incorporado pelos estudiosos do tema como "ativismo virtual" ou "ciberativismo" 7 . No caso das citadas marchas juvenis, o que ocorre, na verdade, é uma mescla de fluxos urbanos e presença nas redes sociais (Rocha, 2012c: 141). Articular, convocar e organizar as manifestações de rua através de um meio virtual tornou a figura do "líder" do manifesto opaca e difusa, de modo que é comum encontrar, nas marchas juvenis ${ }^{8}$

\footnotetext{
${ }^{7}$ Alguns autores também utilizam as expressões "ativismo midiático" ou "ativismo de sofá", sendo esta última comumente utilizada com aspecto pejorativo.

${ }^{8}$ De acordo com a investigação sobre a "Marcha das Vadias", objeto desta pesquisa, todas as versões brasileiras conhecidas, em seus sites, blogs e/ou manifestos, afirmam estar organizadas sob a forma de "coletivos", baseados em liderança horizontal: "O movimento feminista participa dos movimentos
} 
brasileiras, o discurso de que elas se basearam em uma organização de "liderança horizontal ${ }^{9}$ ". Manuel Castells (2003), destacado pensador da "Sociedade em Rede", acredita que esse comportamento é fruto de uma crise histórica, um rearranjo político e social:

"Há uma luta para mudar os códigos de significado nas instituições e na prática da sociedade, é a luta essencial no processo de mudança social no novo contexto histórico [...]. O que caracteriza os movimentos sociais na sociedade em rede é que eles têm de preencher o vazio deixado pela crise das organizações verticalmente integradas, herdadas da Era Industrial" (Castells, 2003: 116).

Colocando Figueiredo e Prazeres (2013) em diálogo com a afirmação de Castells, verificamos que a mudança reside no fato de que a internet surge como um facilitador de tais organizações:

"A dificuldade de se articular as mobilizações surge uma vez que para se efetivar tais movimentos, despendem-se semanas e até meses de reuniões, e ainda há boicotes e perseguições do governo que consegue infiltrar-se nos movimentos, impedindo o levante. [...] A internet muda a dinâmica das reuniões, encontros, articulações e manifestações sociais" (Figueiredo e Prazeres, 2013: 58).

\section{Feministas na Rede}

É também na rede que o movimento feminista tem encontrado um importante lugar político de visibilidade, fato que vem contribuindo para que ganhe destaque no século XXI. O denominado "ciberfeminismo ${ }^{10 "}$ (termo usado para designar a parte do movimento feminista que se compromete com questões como a identidade e os direitos das mulheres no ciberespaço) já é uma realidade em perspectiva mundial. As mulheres engajadas perceberam na internet uma nova brecha onde podem contestar as estruturas, tão arraigadas, do patriarcado. Essa percepção

antiautoritários e privilegia as formas mais espontâneas de manifestação recusando toda organização hierárquica." (Fougeyrollas-Schwebel, 2009: 146).

9 "O principal ponto que os manifestantes procuram deixar claro é a horizontalidade do movimento, do qual se deseja abster qualquer segmento ou orientação política, bem como qualquer movimento de esquerda, a democratização dos direitos de decidir sobre o bem público e não violência das manifestações" (Figueiredo e Prazeres, 2013: 61).

10 "VNS (VeNuS) Matrix, grupo que surge em Adelaide (Austrália) em 1991 e cujas quatro componentes, que provém do mundo da arte (Francesca da Rimini, Julianne Pierce, Josephine Starrs e Virginia Barratt), são as pioneiras na utilização, no início dos anos 90 , do termo 'ciberfeminismo' para apresentar seus trabalhos de experimentação entre o sujeito feminino, a arte e a virtualidade. 'Quando começamos a usar o conceito de ciberfeminismo - esclarece Julianne Pierce - o termo estava aparecendo simultaneamente em outras partes do mundo"” (Miguel e Boix, 2013: 55). 
se faz verdadeira diante da possibilidade que a denominada "rede social", surgida no espaço virtual, traz. A rede social é composta, para além dos bits e programações html, por um conjunto de regras e comportamentos que, devido ao ineditismo dessa ferramenta, ainda estão sendo construídos, gradativamente, pelos usuários e usuárias:

“A informática, a rede, não é somente uma atividade que requer algumas habilidades matemáticas e técnicas determinadas, é também, em palavras de Bernstein, uma cultura, quer dizer, pressupõe um conjunto de normas de comportamento, crenças e atitudes não explícitas nos currículos oficiais ou acadêmicos e que se encontram e se difundem a todo o público através das revistas populares, jornais, best-sellers, filmes, inclusive das piadas e brincadeiras" (Miguel e Boix, 2013: 50).

As ferramentas da cultura digital, como os fóruns virtuais, por exemplo, trazem a oportunidade de repensar as estruturas hierárquicas de fala conduzidas na sociedade off-line. Isto significa dizer que, no ambiente virtual, é possível que as vozes femininas, antes oprimidas, possam "soar" na mesma altura que as vozes masculinas. Para Miguel e Boix (2013), esse fenômeno só é possível, porque, no ambiente virtual, as hierarquias de fala e de participação são mais lineares:

"Para além das construções teóricas, o fator revolucionário, subversivo, transgressor que permite aspirar a pensar novos cenários parece derivar-se intrinsecamente das possibilidades técnicas do espaço virtual e da rede: [...] Desierarquização e criação de modelos mais democráticos com o objetivo histórico vingativo da igualdade de direitos entre homens e mulheres, elaboração de estratégias e pensamentos em rede em que desaparecem conceitos como "centro" e "linearidade" frente ao "diverso", "descentralizado" e "horizontal". Desconstrução de arquétipos através do uso subversivo de dispositivos digitais, protocolos, linguagens de hipertexto, códigos, assinaturas potencialmente variáveis via correio eletrônico" (Miguel e Boix, 2013: 55).

Por se apresentar como um meio a mais de comunicação, em que se pode prescindir de características como idade, estado civil e gênero para mostrar suas ideias, as redes sociais digitais têm trazido avanços significativos para o movimento feminista do século XXI:

"A internet se converteu em um elemento essencial para difundir informação, trocar opiniões, coordenar estratégias e realizar ações com a intenção de construir um mundo mais justo e igual. E o feminismo, que tem muito com que contribuir neste terreno, já é consciente disso" (Miguel e Boix, 2013: 40). 
Todavia, é também verdade que, no espaço virtual, a violência contra a mulher não é uma mera recordação da vida offiline. Diversas formas de agressão e exposição das mulheres, especialmente dirigidas às mais jovens, podem ser observadas na rede a exemplo de práticas como o porn revenge, ciber-bulling e haters. Por isso, é importante destacar que "dessa condição contemporânea significando ao mesmo tempo fim das dicotomias e novas tecnologias, surgem tanto novas possibilidades de emancipação quanto novos modos de dominação" (Vaitsman, 2001: 19).

Desse modo, hoje, é possível observar a criação de muitas páginas na rede social digital Facebook que debatem questões feministas. Muitas são as plataformas virtuais especializadas em receber depoimentos anônimos de mulheres que querem narrar as suas experiências de trauma, como é o caso do blog "http://fuiestuprada.wordpress.com/". Há ainda grande movimentação nas redes sociais digitais para colocar em pauta a temática da chamada "cultura do estupro" no intuito de desnaturalizar os olhares sobre ela.

Estes são alguns exemplos sintomáticos da mudança promovida pela internet no que diz respeito às relações de gênero. O surgimento de espaços de debate criados por jovens mulheres que "sem complexos na relação com as máquinas, em busca de novas linguagens para exteriorizar suas vivências [...] e movidas pelo impulso espontâneo de descobrir novos caminhos de expressão" (Miguel e Boix, 2013: 64), imprime a nós a sensação de estarmos assistindo a uma espécie de releitura atualizada e digital do slogan feminista dos anos 1960: "o privado é político".

\section{Considerações Finais}

Das observações que se apresentaram neste artigo, ganha destaque o fato de ter sido verdadeiramente uma difícil tarefa fazer um recorte de gênero dentro de uma perspectiva histórica das manifestações sociais com a participação da juventude, em razão de que a maioria dos registros que se têm de tais movimentos ou omitem a participação feminina, ou a abordam de maneira indistinta, como se "eles" e "elas" não manifestassem por motivações diversas (Reguillo, 2012) e com características específicas e, portanto, dignas de registro.

Com efeito, vale ressaltar que, a partir dos anos 2000, o ciberespaço tornou-se um lugar muito importante para as novas formas de articulação da juventude e de representação da mulher. Além disso, também contribui para novas configurações de movimentos sociais da juventude e dos novos agrupamentos feministas, pois agora as vozes femininas, não mais silenciadas, também podem ser amplamente difundidas através da rede de compartilhamento nas redes sociais digitais. Esse novo horizonte nos faz acreditar que o campo da comunicação é um rico observatório das novas conformações da juventude e que é possível dedicar a devida atenção às questões de gênero nesses novos espaços de sociabilidade. 


\section{BIBLIOGRAFIA}

- Aguillera, Oscar (2008): "Medios de comunicación en Chile, movimientos juveniles y políticas de la visibilidade”. En: Comunicação, Mídia e Consumo, vol. 5, n 14, pp. 55-68. São Paulo: ESPM.

- Bondi, Liz (1999): "Localizar as políticas de identidade". Em: Debate Feminista. Ed. Especial Cidadania e Feminismo, México / São Paulo: Metis, pp. 245-275.

- Borelli, Silvia Helena; Rocha, Rose de Melo e Oliveira, Rita de Cássia Alves (2009): Jovens na cena metropolitana: percepções, narrativas e modos de comunicação. $1^{\mathrm{a}}$ ed. São Paulo: Paulinas.

- Brandão, Antonio Carlos e Duarte, Milton Fernandes (2004): Movimentos culturais de juventude. $2^{\mathrm{a}}$ ed. São Paulo: Moderna.

- Carmo, Paulo Sérgio do (2000): Culturas da rebeldia: a juventude em questão. São Paulo: Editora Senac São Paulo.

- Castells, Manuel (1999): A era da informação: economia, sociedade e cultura - A sociedade em rede. São Paulo: Paz e Terra.

- Castells, Manuel (2003): A galáxia da internet: reflexões sobre a internet, os negócios e a sociedade. Rio de Janeiro: Jorge Zahar Editor.

- Delphy, Christine (2009): "Patriarcado" Em: Helena Hirata, et al. (orgs.): Dicionário crítico do feminismo. São Paulo: Editora UNESP, pp. 173-178.

- Enne, Ana Lucia (2010): Juventude como espírito do tempo, faixa etária e estilo de vida: processos constitutivos de uma categoria-chave da modernidade. Em: Comunicação, Mídia e Consumo, vol. 7, n 20, SãoPaulo: ESPM, p.13-35.

- Freire filho, João (2007): Reinvenções da resistência juvenil: os estudos culturais e as micropolíticas do cotidiano. Rio de Janeiro: Mauad.

- Fougeyrollas-Schwebel, Dominique (2009): "Movimentos feministas". Em: Helena Hirata et al. (orgs.): Dicionário crítico do feminismo. São Paulo: Editora UNESP, pp. 144-149.

- Lipovetsky, Gilles (2000): A terceira mulher: permanência e revolução do feminino. Editora Companhia das Letras.

- Matos, Olgaria (1998): Paris 1968: As barricadas do desejo. São Paulo: Brasiliense.

- Nunes, Mônica R. F (2013): “A cena cosplay: vinculações e produção de subjetividade”. Trabalho apresentado ao Grupo de Trabalho Comunicação e Sociabilidade do XXII Encontro Anual da Compós, Universidade Federal da Bahia (Anais).

- Pedro, Joana Maria (2006): "Narrativas fundadoras do feminismo: poderes e conflitos (1970-1978)". Em: Revista Brasileira de História, vol. 26, nº. 52, dez. 2006. São Paulo, pp. 249-272, [on line] Disponible en: http://dx.doi.org/10.1590/S0102-01882006000200011 [25/05/2015].

- Pereira, Cláudia (2010): "Juventude como conceito estratégico para a publicidade". Em: Revista Comunicação, Mídia e Consumo, vol. 7, nº. 18, mar. 2010. São Paulo: ESPM, pp. $37-$ 
54. Versão [on line] Disponível http://revistacmc.espm.br/index.php/revistacmc/article/viewFile/184/182 [25/03/2016].

- Piovesan, Flávia (2011): "Direitos Humanos, Civis e Políticos: A conquista da cidadania feminina". Em: Leila Linhares Barsted e Jacqueline Pitanguy (orgs.): O Progresso das Mulheres no Brasil 2003-2010. Rio de Janeiro: CEPIA; Brasília: ONU Mulheres, pp. 58-88, [on line] Disponível em: http://onumulheres.org.br/wpcontent/themes/vibecom_onu/pdfs/progresso.pdf [25/03/2016].

- Rocha, Rose de Melo (2012a): "Juventudes, comunicação e consumo: visibilidade social e práticas narrativas". Em: Lívia Barbosa (org.): Juventudes e gerações no Brasil contemporâneo. Porto Alegre: Sulina.

- (2012b): "Poéticas visuais e processos imagéticos: caminhos para se pensar o consumo". Em: Felício Goiamérico e Tânia Márcia Cezar Hoff (orgs.): Poéticas da mídia: midiatizações, discursividades, imagens, vol. 12. Goiânia: Faculdade de Comunicação e Bibliotecomomia, pp. 33-48.

- (2012c): "Corpos significantes na metrópole discursiva". Em: Revista Significação, ano. 39, vol. 37. São Paulo: ECA-USP, pp. 126-146, [on line] Disponível em: http://www.revistas.usp.br/significacao/article/download/71333/74339 [25/03/2016].

- (2011): “A comunicação é ciência das convergências: ou como enfrentar, criticamente, a dicotomia teoria/prática". Em: Rose Rocha e João Carrascoza (orgs): Consumo midiático e culturas da convergência. São Paulo: Miró Editorial, pp. 11-21, [on line] Disponível em: http://www.miroeditorial.com.br/pdf/ConsumoMidiaticoecultConv.pdf [25/03/2016].

- Soihet, Rachel (2005): "Zombaria como arma antifeminista: instrumento conservador entre libertários". Em Revista Estudos Feministas, vol. 13, nº. 3, setembro-dezembro 2005. Florianópolis: UFSC, pp.591-611, [on line] Disponível em: http://www.scielo.br/pdf/ref/v13n3/a08v13n3.pdf [25/03/2016].

- Trat, Josette (2009): “Movimentos feministas”. Em: Helena Hirata et al. (orgs.): Dicionário crítico do feminismo. São Paulo: Editora UNESP, pp. 149-154.

- Trotsky, Léon (1968): “A luta contra a juventude”. Em: Sulamita de Britto: Sociologia da Juventude IV: os movimentos juvenis. Rio de Janeiro: Zahar, 31-39.

- Vaitsman, Jeni (2001): "Gênero, identidade e família na sociedade contemporânea". Em: Rose Marie Muraro e Andrea Brandão Puppin (orgs.): Mulher, gênero e sociedade. Rio de Janeiro: Relume Dumará e Faperj, pp. 13-20.

- Zanetti, Julia Paiva (2008): "Jovens Feministas: um estudo sobre a participação juvenil no Feminismo". Em: Seminário Internacional Fazendo Gênero 8: Corpo, Violência e Poder. Florianópolis. Seminário Internacional Fazendo Gênero 8: Corpo, Violência e Poder, pp. 1-7. 